\title{
Hay fever: It's nothing to sneeze at
}

\author{
KATHLEEN A. KUK
}

It is not caused by hay, nor associated with fever. Yet the misnomer "hay fever" has clung stubbornly to this allergic disease ever since British farmers in the 1800 s attributed their watery eyes, runny noses and fits of sneezing to the autumn hay harvest.

Today, the allergic condition that afflicts 18 to 20 million Americans is more commonly known as "pollinosis" or "seasonal allergic rhinitis" (as opposed to chronic rhinitis, which persists year round). Modern scientists have made great strides in diagnosing the disease and treating the symptoms, but they are no closer than their predecessors to explaining why some people are prone to allergic attacks while others spend a sniffle-free summer.

Hay fever is actually an allergy to pollen (the powdery grains produced by male plants that are carried by bees or breeze to female plants for fertilization) or to spores of mold (a type of fungus). The ensuing allergic reaction is the unfortunate result of the immune system gone awry.

Normally, white blood cells in the body patrol for and dispose of foreign invaders. But in hypersensitive individuals, harmless substances inadvertently trigger a full-fledged attack. When pollen wafts toward a hay fever sufferer, the white blood cells produce immunoglobin $\mathrm{E}$ antibodies. These foot soldiers of the defense system attach themselves to the surface of mast cells that line the nose, throat, tissues surrounding the eyes, and other mucous membranes. The mast cells then release a powerful array of chemicals, the most potent of which is histamine. It is this chemical warfare that causes the symptoms of hay fever: itchy, runny, and stopped-up noses; tearing, itchy, red, and swollen eyes; coughing, wheezing, and sneezing; and generalized complaints of tiredness, loss of taste and smell, nausea, and diarrhea.

\section{Clues to diagnosis}

The seasonal nature of hay fever is the tip off that your runny nose and cough are not due to a common cold. Spores of pollen and mold peak in certain months, and pinpointing the height of your misery is the first step in identifying the culprit.

There are three main sources of pollen-trees, grasses, and weeds. Folklore maintains that fragrant flowers are the primary vectors of hay fever. These colorful blossoms tend to rely upon insects rather than the wind for pollination, however. It is the dull, odorless plants that pepper the air currents with pollen. The list on page $\mathbf{5 2 0} / 116$ highlights the most polliniferous species of plants.

The budding of trees heralds the debut of spring, and the beginning of hay fever season. Tree pollen count begins to rise in early April and continues through May. Grass pollen season commences in mid-May and lingers into July. Weeds disseminate their pollen in early August through September. This time schedule is generally adhered to in the Midwestern and Eastern states. In warmer locales, allergy seasons are extended and not as clearly defined.

Mold season embraces all of the pollen seasons. 


\section{Sowing the spores of discontent: Common sources of troublesome pollen.}

$\begin{array}{lll}\text { Trees } & \text { Grasses } & \text { Weeds } \\ \text { Elm } & \text { Bermuda } & \text { Ragweed } \\ \text { Maple } & \text { Timothy } & \text { Sagebrush } \\ \text { Walnut } & \text { Orchard } & \text { Thistle } \\ \text { Hickory } & \text { Bluegrass } & \text { Spiny amaranth } \\ \text { Ash } & \text { Red top } & \text { Lamb's quarters } \\ \text { Sycamore } & \text { Rye } & \text { Pigweed } \\ \text { Oak } & & \text { Sorrel } \\ \text { Mulberry } & & \text { Cocklebur } \\ \text { Box elder } & & \\ \text { Cedar } & \\ \text { Pecan } & \\ \text { Juniper } & & \\ \text { Cottonwood } & & \\ \text { Birch } & & \\ \text { Willow } & & \\ \text { Poplar } & & \end{array}$

\section{Landscaping without hay fever: A shopper's guide to nonallergenic or hypoallergenic perennial plants.}

$\begin{array}{lll}\text { Trees } & \text { Shrubs } & \text { Grasses } \\ \text { Holly } & \text { Boxwood } & \text { All grasses are } \\ \text { Flowering dogwood } & \text { Cacti } & \text { suspect; } \\ \text { Russian olive } & \text { Bush honeysuckle many are } \\ \text { Tulip poplar } & \text { Aucuba } & \text { highly al- } \\ \text { Southern magnolia } & \text { Dogwood } & \text { lergenic } \\ \text { Chinaberry } & \text { Oleaster } & \\ \text { Hawthorn } & \text { Azalea } & \\ \text { Stone fruits } & \text { Yucca } & \\ \text { Apple } & \text { Crape myrtle } & \\ \text { Pear } & \text { Lilac } & \\ \text { Western soapberry } & \text { Hydrangea } & \\ \text { Sourgum } & \text { Yew } & \\ \text { Honey locust } & \text { Barberry } & \\ & \text { Hibiscus } & \\ & \text { Flowering quince } & \end{array}$

Outdoor microfungi are released from soil, grass cuttings, and decaying vegetation; indoor mold sources include damp cellars, mildewy fabrics, and standing water in humidifiers. Mold spores are not killed off by frost, and they will once again proliferate if winter temperatures climb.

To further frustrate matters, many persons who are allergic to pollen are also sensitive to house- hold dust, animal dander, cigarette smoke, and noxious fumes. Homes should be kept as free as possible from these aggravating agents. Given the abundance of potential allergens, how is one to know which agent(s) is (are) responsible for your weepy eyes and general malaise? A trip to the family physician or allergist is now in order.

The physician will first ask for an in-depth history of your complaints. Are symptoms worse during certain times of the year? Did a particular event (hiking through tall grass, mowing the lawn, or cleaning the musty basement) precipitate an attack? What plants populate your garden, school yard, or workplace?

A family history of allergy also hints toward a diagnosis of hay fever. If Mom or Dad has allergies, their children have a 50 percent chance of developing them. If both parents are allergic, the odds climb to 75 percent that their offspring will also be affected. Still, it is the tendency toward allergy, and not the sensitivity to a specific allergen, that is inherited.

The physician may then perform a "prick test" to recreate the allergic reaction in an office setting. A single drop of pollen extract is injected under the skin of the inner forearm. An angry red mark that develops within 10 to 20 minutes indicates sensitivity to that particular substance. Unfortunately, more than one allergen may be responsible for the summertime woes. On the bright side, medical researchers have developed a three-pronged attack to combat hay fever.

\section{Avoidance therapy}

The best way to circumvent hay fever symptoms is to avoid the oppressive agent. This is easier said than done, however. The ubiquitous, air-borne spores can permeate the most well-sealed building. Moving to a pollen-free region offers slim hopes of relief. Often, one set of allergies is traded for another. And hay fever refugees who flocked to the arid deserts of Arizona are discovering, to their dismay, that they have destroyed their own haven. In an attempt to duplicate the lush landscape of their native soil, the residents have transplanted the very grasses and trees that were the source of their misfortunes. 
Still, hay fever sufferers can take the following steps to minimize their encounters with allergens:

- Keep doors and windows closed, and use an air conditioner in the spring and summer.

- When landscaping, consult with knowledgeable personnel at a nursery to select nonallergenic plants.

- Have a nonallergic member of the family cut the lawn frequently to prevent grass and weeds from flowering.

- Avoid strenuous exercise on days with high pollen counts.

- If you must dust or mow the lawn, wear a dust mask.

- Install an electronic air purifier to filter pollen, mold, and dust.

- When running a room or automobile air conditioner, close the vents to the outside air.

- Stay indoors during windy, pollen-swept days.

- Schedule your vacation to a pollen-free refuge during ragweed season.

- Avoid hiking in the country if you are sensitive to pollen. Likewise, steer clear of damp woods and streams if you are irritated by mold.

- Keep your home as dust-free as possible.

- Reduce mildew by operating a dehumidifier in damp areas of your home.

- If you own a pet, restrict its wanderings to one room.

\section{Drug therapy}

Drug therapy has three goals: (1) to inhibit the activation of histamine (antihistamines); (2) to block the release of chemical mediators by the mast cells (cromolyn sodium); and (3) to counteract the effects of the chemicals once they are released (decongestants, corticosteroids, anticholingergics, and anti-inflammatory drugs).

The patient-physician team will begin a comprehensive search for the prescription drug combination that maximizes relief while minimizing side effects. Less potent over-the-counter medications are available for the treatment of mild hay fever symptoms. However, sufferers must take care to not become too reliant upon nasal decongestants. Overuse can lead to "rebound rhinitis," which aggravates the stuffiness that the

\section{For more information contact:}

\author{
Asthma and Allergy Foundation \\ of America \\ 1835 K Street, N.W. \\ Suite P-900 \\ Washington, D.C. 20006 \\ American Allergy Association \\ P.O. Box 7273 \\ Menlo Park, California 94026 \\ National Institute of Allergy \\ and Infectious Diseases \\ National Institutes of Health \\ Building 31, Room 7A32 \\ Bethesda, Maryland 20205
}

Allergies: What are they and what to do about them. By J.A. Rudolph and B.M. Rudolph. Jove Publishing, Inc., New York, 1973

The allergy book. By H.V. Dehejia. Contemporary Books, Chicago, 1982

Asthma and hay fever. By A. Knight. Arco Publishing Inc., New York, 1981

The best guide to allergy. By A.V. Giannini. AppletonCentury-Crofts, East Norwalk, CT, 1981

Coping and living with allergies: A complete guide to help allergy patients of all ages. By C.A. Frazier.

Prentice-Hall, Inc., Englewood Cliffs, NJ, 1979

Living with your allergies and asthma. By T. Berland and L. Fischer-Pap. St. Martin's Press, New York, 1983

drug was supposed to relieve originally.

\section{Immunotherapy}

Informally referred to as "allergy shots," this technique attempts to desensitize the immune system to future allergen exposure. Once or sometimes twice a week, gradually increasing 
amounts of a known allergen are injected under the skin. Eventually (15 to 20 injections later), the highest dose that can be tolerated without a serious reaction is attained. This maintenance dose is administered year round, every two to six weeks, to provide continuous protection from allergy symptoms. A slight variation in strength and dosage schedule limits the shots to only before (preseasonal immunotherapy) or during (coseasonal immunotherapy) the allergy season. Nevertheless, immunotherapy incurs the drawbacks of cost, time, and incovenience.

\section{Outlook for the future}

There is currently no cure for hay fever, or, for that matter, any allergic condition. Still, impressive advances in the management of hay fever symptoms may make summertime a season for everyone to enjoy.
(All material in the Patient Health Guide is reviewed by JAOA referees.)

\section{References}

Allergic rhinitis and conjunctivitis: Help for the weeping nose and eyes. By Mark Ballow. Postgraduate Medicine, vol. 76, pp. 197-202, Jul 1984

Allergy in the world: A guide for physicians and travelers. Edited by Alexander Roth. University Press of Hawaii, Honolulu, 1978

Asthma and allergies: An optimistic future. Based on The Report of the Task Force on Asthma and Other Allergies, National Institute of Allergy and Infectious Disease. NIH publication no. 80-388, Mar 1980

The clinical diagnosis and treatment of rhinitis. By J.R. Ransfield. The Practitioner, vol. 227, pp. 1305-11, Aug 1983

Hay fever. By the American Council on Science and Health, Summit, NY, 1985

Non-allergenic native and cultivated plants in Oklahoma: Landscaping with hay fever. By E. Levetin and P. Buck. Annals of Allergy, vol. 52, pp. 166-9, Mar 84

Seasonal allergy update. By Fisons Corporation, New York, 1987 


\section{Information for contributors}

THE JOURNAL OF THE AMERICAN OSTEOPATHIC ASSOCIATION is the official scientific publication of the American Osteopathic Association. Articles are accepted with the understanding that they have not been published elsewhere and that they are not simultaneously under consideration by any other publication.

\section{Concerning acceptable materials}

JAOA has the dual functions of documenting osteopathic contributions in any clinical-scientific subject area and providing clinical teaching for its physician readers; papers are accepted which contribute to one of these goals. JAOA seeks to publish only the best scientific contributions of the osteopathic profession to medical literature. High standards of jurying and editing are therefore maintained.

Priority in publication is given to original work, whether for the specialist or for the general practitioner. An osteopathic slant is expected where appropriate.

For the guidance of osteopathic specialists who are considering where to submit their original work, the following might be offered: JAOA is interested in any clinical problem that a family physician or a specialist in another field might see first; or in any study for which the D.O. wishes to reflect credit upon his own profession. He might submit to a specialty journal papers on topics of specialty interest only.

Both general practitioner and specialist are considered to benefit from the presentation of original work, current reviews with an expert critical viewpoint, clinical research reports, and teaching materials in a variety of clinical fields. JAOA attempts to represent the osteopathic holistic concept in the breadth of its coverage.

Basic science reports can be accepted only in abstract form unless they are specifically related to the clinical sciences. Reprints are used only in the rarest of instances. Letters to the editor, particularly of a kind supplementing or commenting upon scientific articles or providing new information on clinical topics, are encouraged. Book reviews are also welcome for consideration. All book reviews, letters to the editor, research abstracts, and guest editorials are limited to 500 to 1000 words, a maximum of ten references, and two illustrations, where appropriate.

Contributions are accepted from members of the American Osteopathic Association, faculty members in osteopathic colleges, and, in unusual circumstances, from others; in the latter category would mainly be guest lecturers at osteopathic meetings.

In all but rare instances, trainee papers must include the trainer as an author. The coauthorship implies review and additional material from the experience of the senior physician. When the trainee is the sole author, the implication is that the senior physician did not participate in management of the patient(s) or have any part in the construction of the paper. A footnote should identify the trainer in this instance, and this footnote implies the trainer's approval of release of the paper from his department.

\section{Editorial review}

All papers received for JAOA consideration are submitted without identification of author to referees in the field(s) of interest represented by the paper. Notification of acceptance or rejection usually is given within three months after acknowledgement of the paper; publication follows as soon as possible thereafter, depending on the current backlog of papers.

When papers must be rejected for a correctable fault, the editor customarily provides reasons and suggestions. This is in line with a standing policy of the editorial department to give personal help and encouragement to D.O.s who are attempting to learn medical writing. Because of the large number of manuscripts considered by JAOA, however, some are necessarily rejected through no fault in the paper, but because of duplication of subject matter, a preference for original material over some forms of review, or the necessity to establish priorities on the use of limited space.

\section{Mechanical requirements}

Manuscripts should be typed with a ribbon dark enough to be photocopied. The original and four copies should be sent to JAOA. A copy should be kept by the author. Manuscripts should be typed double-spaced (including references and tabular material), with ample margins on each side. All pages should be numbered consecutively. For manuscripts with more than one author, the correspondent should be indicated.

A 150-word abstract that provides a factual summary of the work should be included. This abstract is used in place of a summary.

References are required for all material derived from the work of others. Reference numbers should be assigned in order of citation in the paper. Papers are limited to 30 references. However, if the author has additional references, a notation will be appended to the published paper indicating that readers may contact the author for a list of the additional references. References that are used as general source material but from which no specific information has been taken should be listed in alphabetical order following the numbered references. Each reference to a periodical must include the names of all authors, the complete title of the article, the name of the journal, volume number, date, and inclusive paging. For books, the editor, the name and location of the publisher, and the year of publication must be given. Exact page numbers must be given for all direct quotations.

\section{Illustrations}

Authors are encouraged to submit illustrations that increase understanding of the text. These can include figures, charts, and tables; medical drawings; and photographs, x-rays, or slides. When the point of the illustration can be conveyed in black and white, this is preferable; a limited number of colored illustrations are used, however, when the illustrative purpose would be lost without it.

Engravings can be made from original x-rays or slides, which are then returned unharmed to the author. There is considerable flexibility in the engraving process for photographs, but the preferred form would be $5 \times 7$ black and white glossy prints with good contrast.

Medical art can be professionally done, with hand lettering. However, if an author does not have access to a medical illustrator, it is possible that JAOA can have redrawing and/or typesetting done to provide a professional finished product. Line drawings or charts are best done in India ink on white paper or poster board.

Illustrations should be numbered, with the top indicated, and cited in the text. Permission letters must be obtained for photos of patients if there is a possibility of identification. Captions must be included for all illustrations, and magnification and staining materials should be identified for photomicrographs.

All illustrative material will be returned to the author.

When illustrations have appeared elsewhere, permission is required from both publisher and author. Full information for citation is required by JAOA, as well as the permissions.

\section{Editorial handling, reprints}

All accepted articles are subject to copy editing. Referenced statements are verified with the original article in the literature. Authors receive a typescript (or galley proofs) and proofs of the illustrations for approval before publication. Authors are responsible for all statements, including those changes made by the manuscript editor.

Twenty-five tear sheets are provided free to each author and coauthor. Information for ordering reprints is supplied upon request. Three copies of the JAOA containing the author's article will be sent on request. Papers will automatically be entered for CME credit where appropriate.

No material may be reprinted from JAOA without the written permission of the editor and the author(s). 


\section{MOVING?}

Don't

Forget Us

Attach current mailing label, print your new address, and mail this form to:

Circulation Department

American Osteopathic

Association

142 E. Ontario St.

Chicago, Illinois 60611

Please allow 4-6 weeks for delivery.

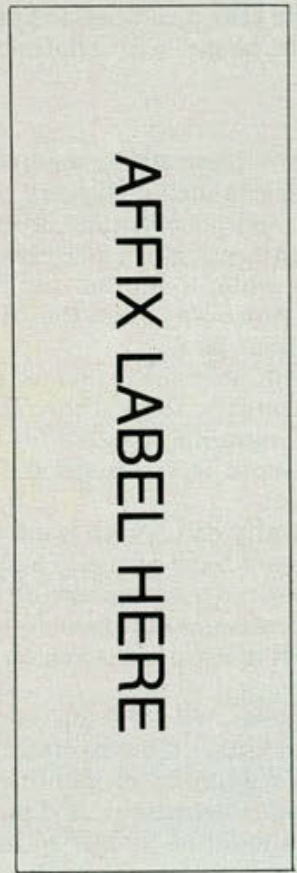

NEW ADDRESS:

Name

AOA Number

Address

\section{advertisers' index}

Beecham Laboratories Fastin, 14-16

Key Pharmaceuticals Nitro-Dur II, 28-30

Lever Brothers, Inc. Dove Bar, 8

Marion Laboratories

Cardizem, 85, 86

Merck Sharp \& Dohme

Vaseretic, $37-41$

Merrell Dow Pharmaceutical, Inc. Seldane, 57-60

Muro Pharmaceutical Inc. Guaifed, 21, 22

Pfizer Laboratories Minipress, 24-26

Riker Laboratories Disalcid, 11, 12

Norflex, 111, 112

Roche Products Inc. Valium, Cover 2-1

Roerig

Sinequan, 45,46

Adria Laboratories, Inc. Kaon CL-10, 3, 4

Smith Kline \& French Laboratories Dyazide, 6

Tagamet, Cover 4

American Osteopathic Association 1987 Convention, 2 Convention Registration Form, 101, 102

Hotel Convention Registration Form, 31, 32, 113, 114
Upjohn Company

Medrol, 49

Micronase, 17, 18, 103, 104

Motrin, Cover 3

Xanax, 52-54 


\section{Motrin 800 mg ibuprofen}

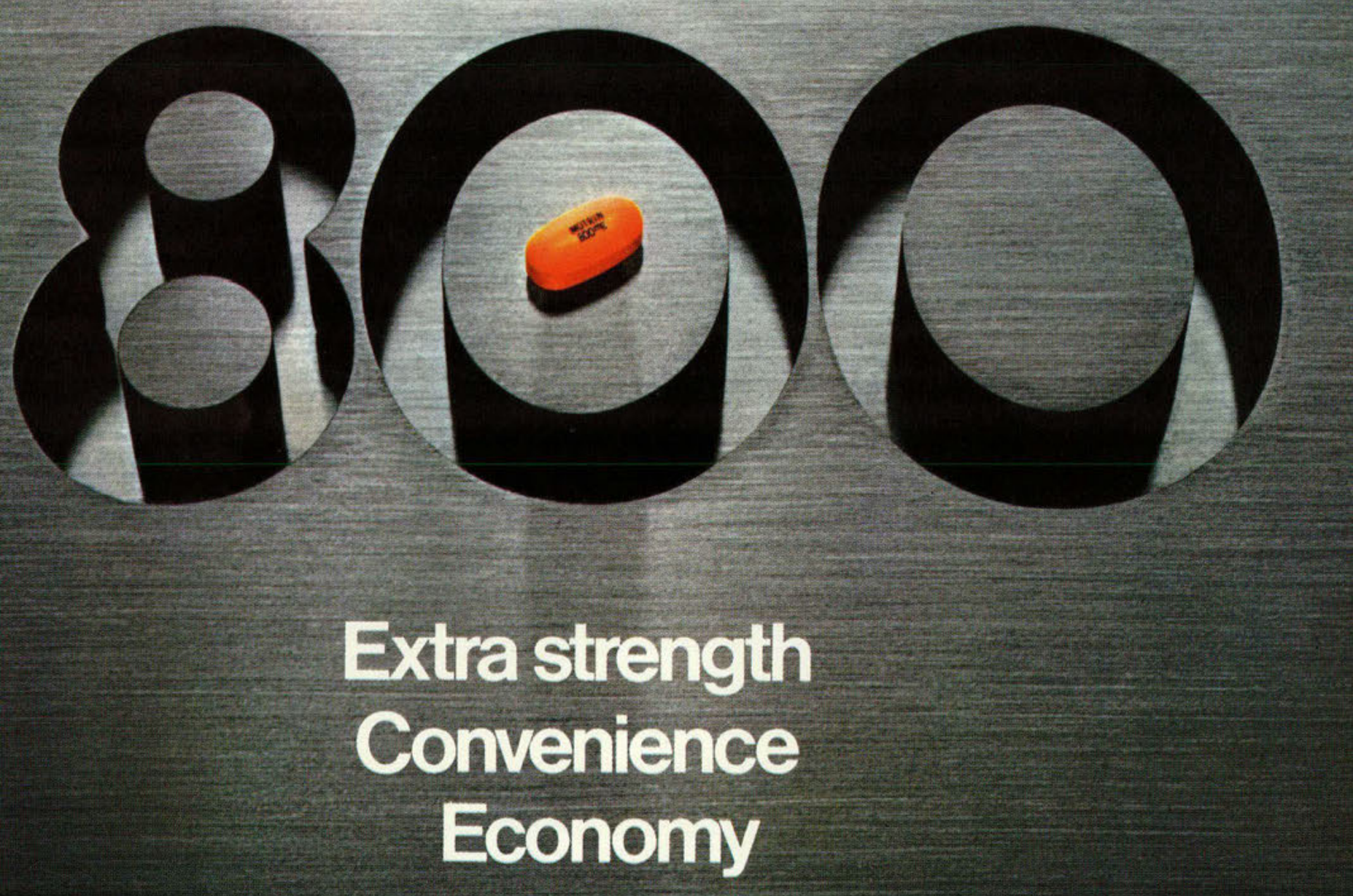




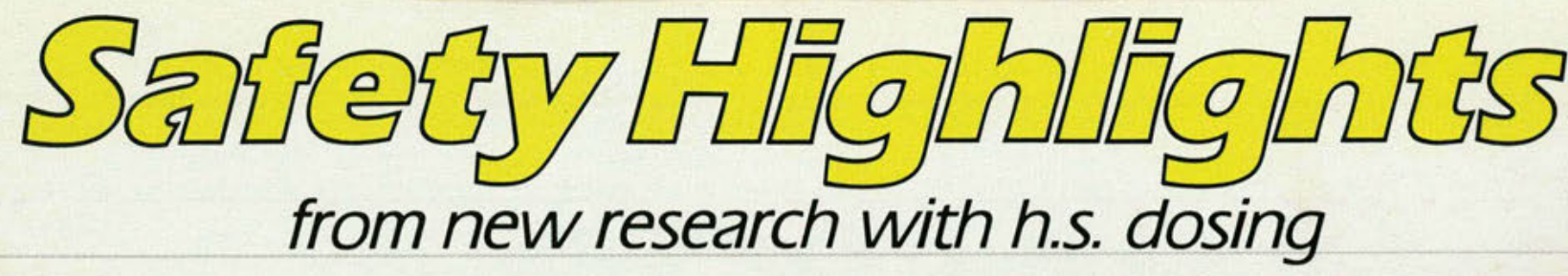

\section{Outstanding CNS safety profile}

Based on a large U.S. study with h.S. dosing

\section{Less potential for theophylline interaction}

Based on a pharmacokinetic study with normal subjects receiving Theo-Dur ${ }^{8+} 300$ mg. b.i.d. and 'Tagamet' 800 mg. h.s. vs. 'Tagamet' 300 mg. q.i.d. ${ }^{3}$

\section{Documentation of safety in older patients}

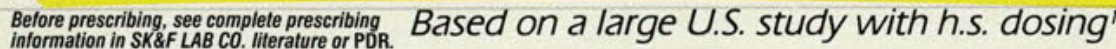
The following is a brief summary.

Indications: 'Tagamel' (brand of cimetidine) is indicated in the short-term treatment of active duodenal ulcer, in maintenance therapy after healing of active duodenal ulcers, in the short-term treatment of active
benign gastric uicer, and in the treatment of pathological hypersecretory disorders (i.e., Zollinger-Ellison Syndrome, systemic mastocytosis and multiple endocrine adenomas.)

'Tagamet' HCl (brand of cimetidine hydrochioride) may be administered parenterally to hospitalized patients with pathological hypersecretory conditions or intractable ulcers, or to patients who are unable to take oral medication.

Clinical studies have indicated that suppression of nocturnal acid is the most important factor in duodenal ulcer healing. 'Tagamel' $800 \mathrm{mg}$. h.s. is the regimen of choice for most patients for acute duodenal ulcer therapy, as it provides a high healing rate, maximal pain reliel, a decreased potential for drug interactions,

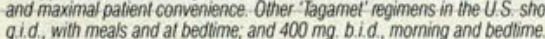

In active duodenal uicer, concomitant antacids should be given as needed for relief of pain; however, simultaneous administration is not recommended.

Contraindications: There are no known contraindications to the use of Tagamet

Precautions: While a weak antiandrogenic effect has been demonstrated in animals, 'Tagamet' has been

shown to have no effect on spermatogenesis, sperm count, motility, morphology or in vitro fertilizing

In a 24-month toxicity study in rats at dose levels approximately 910.56 times the recommended human dose, benign Leydig cell tumors were seen. These were common in both the treated and control groups, and the incidence becan

Rave instances of cardiac arthythmias and hypotension have been reported following the rapid administra. tion of 'Tagamel' ' $\mathrm{HCl}$ (brand of cimefidine hydrochioride) Injection by intravenous bolus.

Symplomatic response 10 'Tagamer' therapy does nol preclude the presence of a gastric malignancy. There have been rare reports of transient healing of gastric ulcers despite subsequently documented malignanc;

Reversible confusional states have been reported on occasion, predominantly in severely ill patients. 'Tagamet' has been reported to reduce the hepatic metabolism of warlarin-type anticaagulants, phenytoin, propranoiol, chlordiazepoxide, diazepam, lidocaine, theophyyline and metronidazole. Clinically significan effects have been reported with the wartarin anticoagulants; therefore, close monitoring of prothrombin administered concomilantly. Interaction with phenytoin, lidocaine and theophylline has also been reported to produce adverse clinical effects

However, a crossover study in healthy subjects receiving either 'Tagamet' $300 \mathrm{mg}$. q.id. or $800 \mathrm{mg}$. h.s. concomitantly with a $300 \mathrm{mg}$ b id dosage of theophrline (Theo demonstrated less alteration in steady.stale theophylline peak serum levels with the $800 \mathrm{mg}$. his. regimen particularly in subjects aged 54 years and older Data beyond ten days are not available. Note: All patients receiving theophylline should be monilored appropriately, regardiess of concomitant drug therapy.)

* The most commonly reported adverse events were nausea, diarrhea, an headache: incidences were similar to those for placebo. Other adverse effects have been reported with 'Tagamet' therapy. Please see prescribing information for a complete description of precautions, adverse reactions. and drug interactions.

theophylline anhydrous sustained action tablets:

Key Pharmaceuticals, Inc.

1. Data on file, Smith Kline \& French Laboratories.

2. Sabesin, S., et al.: Postgrad. Med.

(special report, interim data). $p \rho$

43-46, Nov. 1985

Lack of experience to date precludes recommending 'Tagamet' for use in pregnant patients, women of risks; generally, nursing should not be undertaken in patients taking the drug since cimetidine is secreled in Adverse Reactions: Diarthea, dizziness, somnolence, headache, rash, gynecomastia. Reversible arthralgia, myalgia and exacerbation of joint symptoms in patients with preexisting arthritis have been reported. Riversible contusional stales (e.g. mental contusion, agitation, psychosis, depression, anxiety, impolence in patients with pathological hypersecretory disorders receiving Tagamel', particularly in high doses, for at least 12 months, has been reported. Reversible alopecia has been reported very rarely. Decreased white blood cell counts in 'Tagamet' treated patients (approximately 1 per 100,000 patients), including agranulocytosis (approximately 3 per million patients), have been reported, including a few reports of recurrence on rechalienge. Most of these reports were in patients who had serious concomitant ilinesses and received drugs and/or treatment known to produce neutropenia. Thrombocytopenia (approximalely 3 per million patients) and a few cases of aplastic anemia have also been reported increased serum trans aminase and creatunine, as well as fare cases of tever, interstitial nephritis, uninary retention, pancreabtis and allergic reactions, including hypersensitivily vascuiltis, have been reported. Reversible adverse hepatic effects, cholestatic or mixed cholestatic hepalocellular in nature, have been reported rarely. Because of the predominance of cholestauc leatures, severe parenchymar injury is considered highiy unikely. A single case of biopsy-proven periportal hepatic fibrosis in a patient receiving 'Tagamet' has been reported.

How Supplied: Tablets: $200 \mathrm{mg}$. tablets in bolles of 100; $300 \mathrm{mg}$. lablets in boltles of 100 and Single Unit Packages of 100 (infended for institutional use only): $400 \mathrm{mg}$. tablets in bottles of 60 and Single Unil Packages of 100 (intended for institutional use only); and in $800 \mathrm{mg}$. Tiltabs tablets in bottles of 30 and Single Unit Packages of 100 (intended for insfitutional use only.

Liquid: $300 \mathrm{mg} / 5 \mathrm{ml}$, in $8 \mathrm{fl} .02$. (237 ml.) amber glass bottles and in single dose units $(300 \mathrm{mg} / .5 \mathrm{ml}$ ), in packages of 10 (intended for institutional use only)

Injection:

Vials: $300 \mathrm{mg} / 2 \mathrm{ml}$. in single dose vials, in packages of 10 and 30 , and in $8 \mathrm{ml}$. multiple dose vials, in packages of 10 and 25 .

Prefilled Syringes: $300 \mathrm{mg} / 2 \mathrm{ml}$, in single-dose prefilled disposable syringes

Plastic Containers: $300 \mathrm{mg}$. in $50 \mathrm{ml}$. of $0.9 \%$ Sodium Chloride in single dose plastic containers, in packages of 4 units. No preservative has been added.

ADD.Vantage * Vials: $300 \mathrm{mg}, 2 \mathrm{ml}$. in single-dose ADD.Vantages Vials, in packages of 25.

'Tagamet' $\mathrm{HCl}$ (brand of cimetidine hydrochloride) Injection premixed in single-dose plastic containers is

manufactured for SK\& F Lab Co. by fravenol Laboratories, Inc., Deerfield, IL 60015 .

ADD.Vantages is a trademark of Abbott Laboratories.

BRS.TG:L72

Date of issuance Mar 1987
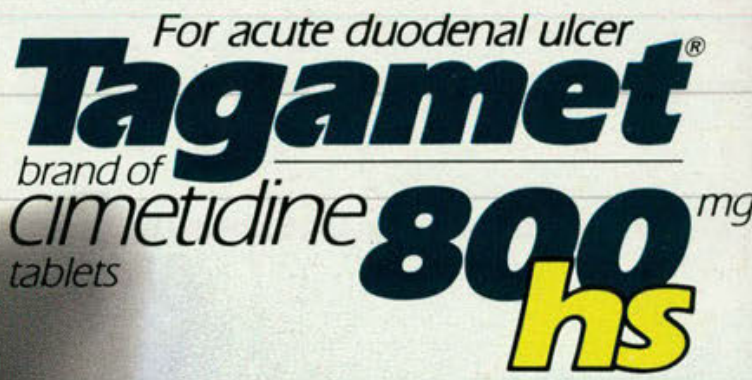